\title{
Algunos problemas lexicográficos en El Periquillo Sarniento
}

A pesar de la mucha atención que ha recibido la obra maestra de Fernández de Lizardi, raras han sido las pesquisas dedicadas al lenguaje mismo de la novela. Algunas de las notas explicatorias incluídas en la edición de 1816 y, con varias adiciones en las ediciones posteriores, no proporcionan definiciones de los términos y frases verdaderamente problemáticos usados en el texto. Asimismo, el breve glorioso que aparece en la edición de 1830-31 y en otras muchas consiste principalmente de aztequismos que no ofrecen dificultades lexicográficas.

En cuanto a los diccionarios de americanismos y mexicanismos, imprescindible para todo investigador del lenguaje de Lizardi es el Vocabulario de mexicanismos (México, 1899) del gran lexicólogo Joaquín García Icazbalceta, quien empleó las obras de Lizardi como fuente principal para sus citas corroboradoras. Pero este léxico abarca solamente desde la letra $A$ hasta $H \mathrm{y}$-aunque es mucho más completo que los diccionarios de Santamaría, Malaret, Ramos y Duarte, etc.también deja por solucionar bastantes problemas.

Con respecto a las voces $\mathrm{y}$ expresiones que anotamos a continuación, se cae de su peso que no las hemos podido hallar en ninguna parte fuera de las novelas de Lizardi, y también que han resistido rigurosamente una clarificación absoluta, a pesar del número considerable de peritos a quienes hemos acudido con este propósito.

1. agua de la palata: "También te ruego que no consientas que las señoras viejas me acaben de despachar 
con buena intención echándome caldo de substancia ni agua de la palata."1

"...así como el médico que le manda al moxibundo agua de la palata por consuelo de sus dolientes, pero él sabe de cierto que no tiene remedio."

Somos de la opinión que debiera ser "agua de la paleta" (como se encuentra en la edición de 1897) y que tiene el sentido figurado de agua dada al moribundo a guisa de consuelo, por medio de un cucharón o paleta. En efecto, el traductor Eugene Pressley ofrece "water out of a dipper."3 Pero esta traducción, como otras muchas de Pressley, no es de una autoridad final, porque el traductor, aunque refleja admirablemente el espíritu picaresco de la novela, no pretende acertar en traducciones exactas en cada caso.

El profesor Luis Leal propone la posibilidad que "agua de la palata may be a corruption of a nahuatl word such as aguapacle, 'medicamento de encina." "4 Respecto a aguapacle, Robelo explica: "Aguapacle (AHUA-PATLI: ahuatl, encina; patli, medicamento). Yerba medicinal..."5

2. hacer lo del cohetero: “...por entonces no tenía mejores conocimientos que el coime y los concursantes del juego, pues aunque cada rato encontraba muchos de los que antes se decían mis amigos, unas veces hacía yo lo del cohetero por no verlos de vergüenza, y otras, que eran las más, ellos hacían que no me veían a mí, o ya por no afrentarse con mi pelage, o ya por no exponerse a que les pidiera alguna cosa."6

Es posible que esto signifique fingir que está uno muy ocupado, como el cohetero que en las procesiones está vigilando los cohetes, mirando arriba, etc. ¿O posiblemente que el ruido de los cohetes le haya hecho sordo $\mathrm{y}$, por eso, descuidado?

1 Lizardi, El Periquillo Samiento, Edición Stylo (México, 1942), tomo II, p. 485 .

2 Lizardi, La Quijotita y su prima (México, 1897), p. 178.

3 The Itching Parrot, ed. Katherine A. Porter (New York, 1942), p. 289.

4 Carta a J. E. Davis, fechada el 26 de abril, 1955.

5 C. Robelo, Diccionario de aztequismos (México, 1912), s. v.

6 El Periquillo, II, 107. 
3. (gente) de la hoja: "Como todas las casas que visitábamos eran de aquellos y aquellas que llaman de la 'hoja,' me daban mis estregadas terribles, especialmente las mujeres." 7

Al parecer, esta frase quiere decir algo así como "rufianesco"; es con este sentido que figura en Guzmán de Alfarache, Aventuras del bachiller Trapaza, y en otras de las novelas picarescas. 8

También se ha creído que "puede querer decir los marihuanos, que hoy en día gente de hoja se refiere a éstos."9 Interesante teoría, pero nótese: "El polígrafo don Victoriano Salado Alvarez cree ... que la marihuana no empezó a usarse en México sino hasta muy entrado el siglo XIX. Para asegurarlo se apoya, principalmente, en que en El Periquillo, no se menciona con ese nombre ni por ninguno de germanía mexicana."10

Finalmente, mencionaremos dos locuciones que posiblemente tengan alguna relación semántica con dicha expresión: "Ser uno de la hoja. Ecuador. Ser de la cuerda, de la misma camarilla..."11 y "De la hoja movida, met. y fam., se dice de la persona de poco juicio, voluble e inquieta, sin fijeza."12

4. justicia: “Conocí que era Culás el 'guitarristo,' porque tocaba un jarabe y una justicia en la guitarra a lo rasgado que le hacía hablar.'13

Parece indudable que es tipo de baile o canción popular, pero la única evidencia que hemos podido hallar es: "The justicia evidently referred to [a] particular kind of music." 14

7 Ibid., I, 186.

8 Véase J. E. Davis, Estudio lexicográfico de El Periquillo Samiento, University Microfilms, Ann Arbor, Michigan, 1956, p. 102, s. v. hoja.

- A. L. Donnel, El lenguaje del Pensador Mejicano (México ,1950), p. 90.

10 Artemio de Valle Arizpe, Cuadros (México, 1943), p. 229.

11 A. Malaret, Diccionario de americanismos, 3a. ed. (San Juan, Puerto Rico), 1946, s. v. hoja.

12 R. Caballero, Diccionario de modismos de la lengua castellana (Bueros Aires, 1908), p. 462.

1.3 El Periquillo, I, 421.

14 K. B. Gray, Traditional Love and Cusioms in Fernandez de Lizardi's 'El Periquillo Samiento' 1936, p. 202. 
5. llevarla cocida: “¿ Cuántos [soldados] van a fuerza a la campaña, que no irían si los generales al aproximarse al enemigo publicaran, como Gedeón, un bando para el que se sintiera débil de espíritu se fuera a su casa? Yo aseguro que no pasarían de trescientos valientes en el ejército más lucido y numeroso, si no la llevaban muy cocida, o les instigaba la codicia del saco."15

¿Significa estar endurecido, o "curtido", en el sentido de tener mucha experiencia? Cfr. "Estar uno cocido en una cosa, fig. y fam. Estar muy experimentado o versado en ella." (Diccionario de la Academia, s. v. cocido).

6. la de pita: "-Pues has de saber -le dije--, que cuando fuí a dar a la cárcel, donde tuve el honor de conocerte, fué de resultas de una manotadilla de amigos... -Conque, ¿en qué paró usted por fin, y cómo fué eso de que fuera a dar a la de pita por nosotros?"'16

Esto tal vez se referirá a la cárcel. En Don Catrín encontramos lo siguiente: “... y yo al hospital en calidad de preso. Por fin me dieron por sano y fué preciso salir del mesón de la pita; fuí a mi casa..."17 Mesón de la pita, según el profesor J. R. Spell, "se refiere evidentemente a la cárcel. La pita -entre sus varias significaciones- es una especie de agave, y tal vez se aluda aquí a una bebida alcohólica, el pulque, que se hace de un líquido extraido de dicha planta."18

Nótese también que una de las expresiones mexicanas para emborracharse es "ponerse pita o pisto,"19 y, curiosamente, que en el argot español pita quiere decir aguardiente.20

7. sierra de gallo, $y$

8. sierra inglesa: "-Mira, no se puede ensamblar la

15 El Periquillo, II, 375-376.

16 Ibid., II, 372-373.

17 Lizardi, Don Catrin de lat Fachenda, ed. J. R. Spell (México, 1944), p. 76.

18 Ibid., p. 268, nota.

19 Investigaciones Lingïisticas (México, 1933-1938), tomo II, p. 135.

20 L. Besses, Diccionario de argot español (Barcelona, sin año), s. v. pita; y P. Serrano Garcia, Vocabuldrio ilustrado del caló delincuente (Madrid, 1950), s. v. pita. 
pierna, porque el hueso está hecho astillas (y era verdad). Es menester cortarla por la fractura de la tibia, pero para esto se necesitan instrumentos y yo no los tengo.

- ¿Y qué instrumentos se han menester? -preguntó el Aguilucho.

Una navaja curva - le respondi-, y una sierra inglesa para aserrar el hueso y quitarle los picos.

—Está bien -dijo el Aguilucho.

$\mathrm{Y}$ se fueron.

A la noche vinieron con un tranchete de zapatero $y$ una sierra de gallo. Sin perder tiempo nos pusimos a la operación. 21

¿Eran tipos de sierras quirúrgicas?

Hay posibilidad, si bien remota, que sierra de gallo se refiriera a una sierra de segunda mano; véase "Gallo. 3. Méx. Lo que se obtiene de segunda mano. 'Vestirse de gallos' es vestirse con ropa que otro ha usado antes." 22

9. turca: "...le encargué que me vendiese mi cama, libros, manto, turca, reloj, y cuanto consideré que podía valer algo." 23

En cuanto a esta palabra, nos encontramos en el mismo apuro que la señorita Gray cuando ella afirma: "It has not been possible to determine what the author meant by the word turca." "24

En Uruguay existe la expresión "cama turca", siendo ésta un tipo de catre.25 Pero el contexto parece invalidar tal. solución, pues es difícil que un estudiante de pocos recursos tenga al mismo tiempo una cama $y$ un catre.

10. verónico: El baratillero entonces le dijo a un amigo suyo que estaba en su tienda, que fuera conmigo y no me dejara hasta que yo entregara al que me habia

21. El Periquillo, II, 382.

22 Malaret, op. cit., s. v. gallo.

23 El Periquillo, I, 342.

34 Gray, op. cit., p. 154.

25 D. Wogan, Boletín de la Biblioteca Attiguts-IWasbington, Montevideo, junio de 1946, p. 38 , 
dado a vender la capa, que se conocía que yo era un buen verónico, pero que aquella capa la había robado a don Celidonio un mozo que tenía, conocido por Periquillo Sarniento."26

(En la primera edición, se lee: ". .que yo era un verónico," omitiéndose el adjetivo "buen".) Para verónico Pressley pone la traducción "honest-looking fellow,"27 lo cual se amolda perfectamente al contexto. Pero, ¿de dónde deriva el traductor su autoridad para esto?

El profesor Bernardo Gicovate es de la opinión que el término "seems related, in meaning as well as sound, to the legend of La Verónica." 28 Y, muy interesante también, el doctor Renato Rosaldo nos propone que posiblemente verónico tenga alguna relación con el vocablo tauromáquico verónica, sobretodo en vista de que se incluye en el párrafo la palabra "capa." Es decir, ¿significaría verónico, en aquel entonces, el poseedor o el manipulador de una capa?

En la siguiente sátira sobre el culteranismo, el adjetivo verónico se emplea con el sentido de blanco y -figuradamente- inocente, lo que bien pudiera relacionarse semánticamente con el uso en El Periquillo:

$$
\begin{aligned}
& \text { Caracteres de crueldad, } \\
& \text { rígida escribes, Inés, } \\
& \text { con esos de oro cabellos } \\
& \text { en verónico papel. } \\
& \text { Vago en tus rizos el aire. } \\
& \text { descifre letras, si bien } \\
& \text { libar las del rostro flores } \\
& \text { delinque ya en descortés. } 29
\end{aligned}
$$

Algunos de los problemas más curiosos y difíciles son términos del juego. Que estos términos no eran -ni en aquellos días- de comprensión fácil es admitido por el mismo Lizardi: "Bien pudo Periquillo haber explicado aquí el mecanismo de estas fullerías, pero sin duda las calló con estudio,

E. P. S., II, 81.

The Itching Parrot, p. 172.

Carta a J. E. Davis, fechada el 26 de octubre, 1955.

A. Castillo Solórzano, Tarder entretenidas [1625] (Madid, 1908), p. 311. 
deseando prevenir a los lectores incautos en los peligros del juego, sin enseñarlos a maliciosos. Es bueno saber que hay drogas, pero no saber hacerlas." 30

La mayoría de estas voces y expresiones de tahures aparecen en cuatro lugares en la novela, los cuales citamos aquí seguidos para evitar repetición excesiva.

(a) "Pues, ¿tú piensas que está en ellos el errar o acertar? No, hijo, está en mis manos. Yo los conozco y sé que juegan la apretada figura; y así los amarro los albures de manera que si ponen poco, dejo que venga la figura; $y$ si ponen harto, se las subo al lomo del naipe."31

(b) "No hay mejor regla ni más segura, que los 'zapotes, deslomadas, rastrillazos' $y_{i}$ otras diligencias de las que yo hago, y aun éstas tienen su excepción, que es cuando se la advierten a uno y le ganan con su juego..."32

(c) "En verdad que era fullero el Aguilucho, pero no tan diestro como decía; porque en un albur que iba interesado con cosa de doce reales, hizo una deslomada tan tosca y a las claras, que todos se la conocieron..."33

(d) "Para entrar en esta carrera y poder hacer progresos en ella, es indispensable que sepas... dar rastrillazo, hacer la hueca, dar la empalmada, colearte, espejearte, y otras cositas tan finas y curiosas como éstas." 34

11. jugar la apretada figura: Véase arriba el párrafo (a). Según el contexto, esta frase significa jugar o apostar a un naipe de figura de menor valor. Así lo entiende Pressley: "to play the low face card." 35

12. deslomada: Véanse arriba los párrafos (b) y (c). El sentido normal de deslomada es, desde luego, la acción y efecto de romper los lomos de algo o de alguien. Ahora es posible que esta maniobra pueda tener que ver con el romper,

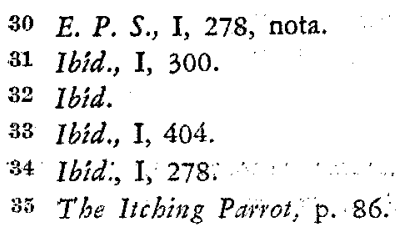


el quitar o el marcar, de una manera u otra, el lomo de las cartas. Sin embargo, a nuestro parecer deslomada quería decir una trampa que consistía en mover subrepticiamente una carta al lomo de la baraja, porque nótese: “...y así les amarro los albures de manera, que si ponen poco, dejo que venga la figura; y si ponen harto, se las subo al lomo del naipe [la baraja]." 36

Donnelli7 y Mapes ${ }^{38}$ opinan que deslomada equivale aquí a "despropósito, patochada," y es cierto que a veces y como localismo la palabra puede llevar tal significado. Pero en nuestra opinión esa interpretación no se ciñe muy bien al contexto de las dos citas.

13. rastrillazo, o dar rastrillazo: Véanse arriba los párrafos (b) y (d). Nos parece muy probable que la expresión dar rastrillazo tenga parentesco con la locución usada en el Siglo de Oro dar (un) astillazo, que significaba una trampa en que una carta se metía fraudulentamente entre las demás, sin que los otros jugadores notaran el truco. En Rinconete $y$ Cortadillo leemos lo siguiente: "Por último, Rinconete se atrevía 'a dar un astillazo' al más puntado mejor que dos reales prestados." 39 Rodríguez Marín aclara que "dar astillazo era meter solapadamente una carta entre las demás, para quitar las suertes que derechamente venían a su contrario." 40 No parece díficil que dar astillazo y dar rastrillazo puedan ser variantes de la misma frase. La primera $r$ en rastrillazo podría manifestarse por influencia de $d a r$, y en cuanto a la segunda $r$, cfr. "Lat. rastellum Sp., Braz., OPtg. rastrillo and OSp., Arag., Murc., Ptg. rastillo, etc." 41 Quizá haya también paralelo semántico en el uso, en varias partes

\footnotetext{
36 E. P. S.; I, 300.

37 Donnell, op. cit., p. 88.

38 El Periquillo Samiento, ed. E. K $\mid$ Mapes (texto para estudiantes (Nueva York, 1942), donde se da la traducción "blunder" (p. 78).

39 M. de Cervantes, Rinconete y Cortudillo, ed. F. Rodríguez Marin (Madrid, 1920), p. 406.

40 Ibid., nota.

4il Yakov Malkiel, "The Etymology of Hispanic "restolho, rastrojo, rostoll,", Romance Pbilology, Vol. I (Feb. 1948), p. 218, et passim.
} 
de Hispanoamérica, de las voces rastrillar y rastillar con el sentido de robar o hurtar. 42

14. hacer la hueca: Véase el párrafo (d). Esta expresión querrá decir o doblar la baraja hacia adentro para que aparezca cierto naipe, o hacer pequeña concavidad en cierto naipe, la cual se puede sentir con la mano al barajar o cortar. Si tal interpretación es acertada, la frase es sinónima de la antigua locución dar boca de lobo que se halla en Rinconete $y$ Cortadillo, etc. 43

15. dar la empalmada: Véase el párrafo (d). Debe significar ocultar un naipe en la palma de la mano (véase " $E m$ palmar. To palm (a card)." - Holt Spanish and English Dictionary, New York, 1955).

16. Colearse: Véase el párrafo (d). Colear, según Augusto Malaret4 y Roberto Restrepo, 45 puede significar petardear, no pagar; y aunque aquellos lexicólogos no registran la forma reflexiva del verbo, ese sentido se ajusta bastante bien al contexto en párrafo $(d)$.

17. espejearse: Véase el párrafo (d). Para la explicación de este embuste, no tenemos teoría alguna, a menos que signifique usar un espejo para ejecutar la trampa.

JACK EMoRy DAvis, Universidad de Arizona.

42 Véase J. E. Davis, op. cit., p. 167 , s. v. rastrillazo.

43 Ibid., p. 21.

44 A. Malaret, Los americanismos en la copla popular y en el lenguaje culto (New York, 1947), p. 45.

45 R. Restrepo, Apuntaciones idiomáticas y correcciones de lengudie (Bogotá, 1943), s. v. 
